Journal of Economics and Behavioral Studies

Vol. 7, No. 1, pp. 1-12, February 2015 (ISSN: 2220-6140)

\title{
In competency Aspects of Microfinance Industry: Via SFA approach
}

\author{
*Madiha Riaz, Pathiban S. Gopal \\ Universiti Sains Malaysia, Pulau Penang, Malaysia \\ *madihatarar@hotmail.com
}

\begin{abstract}
Microfinance is a well known terminology used for microcredit and financial services for financially deprived community. Through informal, semi-formal and formal ways different institutions has been providing these services. Expenditure of the industry is considered to be high because of its inherent structure, dealing with small loans and having high risk of recovery. Therefore, expected inefficiency is greater than its profit. There are several factors and reason. Through this study, we analyzed few factors which have a positive or negative relation with the inefficiency of Microfinance in Pakistan. Stochastic frontier analysis (SFA) is used for weighing up a relationship between inefficiency and its determinants. It is seen that the average efficiency of this sector is low, on average the highest technical efficiency score is 87 only. Age and number of clients have a negative relationship with inefficiency whereas for other variable's relationship is conditional on Microfinance Institutions (MFIs) working status. The number of women borrowers and average loan balance has been incorporated in the study to analyze the focus of MFIs, either on mission drift or achievement. We found that microfinance banks (MFBs) are drifting away, however, Non Government Organizations (NGOs) and Rural Support Programs (RSPs) are fulfilling their social mission efficiently. We did not find a strong evidence of mission drift in the industry because microfinance banks considered their social mission on second priority. Hence, if MFBs are drifting away from their social services, it is not unexpected.
\end{abstract}

Keywords; Efficiency, Micro financing, Stochastic Frontier Analysis, Technical efficiency, Mission drift, Women Borrowers.

\section{Introduction}

Microfinance (MF) perpetrated it recognition all over the world because of its remarkable achievement (Ledgerwood et al., 2013). All over the developing world, deep rooted and multifaceted poverty annihilation is becoming a challenge, despite of substantial caution from beginning to end in a mixture of poverty alleviation programs, it is becoming hard to combat the pervasive social and economic poverty. Microfinance is one of the influential tools to defeat poverty, conceptualized by Dr Muhammad Yunus in 1976, in Bangladesh. Afterward, it multiplied in geometric progression and chased by almost all the nations, particularly developing due to its plain, yet effectual structure. Several studies (Johansen and Nilsson, 2007; Kabir and Huo, 2011) have proven its verity, as an appropriate technique to empower the underprivileged and to enlarge their earning propensity. It is generally believed that the success of microfinance lies in its fundamental role of easy credit provision to poor section, economically active but financially constrained, that has been ignored by the moneymaking commercial sector for years. Supportive services of microfinance Institutions (MFIs) have revealed sound effect on economic development (Khandker, 2005; Baido, 2008). MF industry in Pakistan is considered among one of the best regulated industry in the world, yet it is facing terrible challenges for survival. Since independence in 1947, Pakistan is mugging stiff challenge due to weak economic base. It has to confront several issues simultaneously; for example, regional conflicts, economic crises, natural disasters, governance issues, conflicts with neighbor countries, etc. Further, inherent issues within the structure of the economy also cannot be ignored that include corruption, nepotism, misusage of resources and powers, political instability, violence, terrorism and almost no accountability no governance. The exceedingly unstable security situation, rising energy shortage, a weak tax structure, falling trade, falling investment, and food price inflation are worsening the situation day by day not only for the country but also for the industries working there. 
The present situation and reported measures of economic indicators in Pakistan are illustrating a misanthropical situation and an expected increase in poverty, which was previously recorded as $50 \%$ of the total population in 2011 by United Nation Human Development (CIA). In this scenario, Microfinance industry in Pakistan is a marvel innovation, which emerged as a promising segment, and developed at a faster speed by means of novel contestant and products. Although Microfinance in Pakistan is dated back to the 1960s when Comilla Project was experimented with microcredit initiatives yet, it gains popularity in the current decades owing to adopting new strategies and an active participation by the state bank of Pakistan (SBP), for the improvement of this sector. Profitability and performance index of MFIs is fluctuating, however recuperating. The background of MFIs in Pakistan was primarily non-regulated, but after 2000-01 due to the enforcement of microfinance ordinances by SBP, a pattern has emerged for regulating the industry, that ensure improvement. There are three peer groups of retail players in overall Pakistan's microfinance industry: microfinance banks (MFBs), Non Government microfinance institutions (NGO-MFIs) and rural support programs (RSPs). Microfinance banks are licensed under the Microfinance Institutions Ordinance 2001, and have been working under the regulatory and supervisory framework of SBP. The other two categories of MFIs are scheduled under one of these separate legislative frameworks that include; the Societies Registration Act, 1860, The Voluntary Social Welfare Agencies Ordinance, 1961, The Trust Act, 1882, and the Companies' Ordinance, 1984. There are, at least five types, including 2001 ordinance, of legislative frameworks that are of relevance for the microfinance industry in Pakistan. (PMN, 2011, The SBP Microfinance unit). According to Pakistan Microfinance Network (PMN) there came a drastic change in this sector after the year 2005.Previously, there were unregulated microcredit suppliers relying on traditional delivery methods. However, currently, presentation of microcredit shifts to microfinance with a regulated and broader vision. The access to finance via branchless banking and diverse lending models are setting up the sector on sustainable roots.

Nonetheless, it is considered that 90 percent of the microfinance in Pakistan is still unexploited because of a variety of factors, including the fact that the operating costs are quite high: from 18 to 20 percent. The potential market is between 25 and 40 million whereas, the balance sheet of the sector is said to be Rs. 60 billion (PMN, 2013). This figure can be multiplied significantly with a corresponding growth in the industry. There are so many excuses which are given for the (in) efficiency of Microfinance industry working in a developing and a deteriorating environment; for instance, half of the population is underserved and all of them need a financial support for uplifting, demand is much greater than the supply of funds from MFIs and for MFIs, the infrastructure of the industry is weak, and cost of operation is high, etc... Through this study, we attempt to locate some of (in) efficiency factors of MF industry in Pakistan by applying the stochastic frontier analysis, proceeding to analyzing and reporting the technical efficiency level of the industry. This technique has been applied first time in MF industry in Pakistan and will be a valuable addition in research for further application and policy formulation. We will strive to find the answer for following questions.

- Whether MFIs in Pakistan are efficient/inefficient?

- What are the factors of efficiency/inefficiency?

- Do the specific characteristics of MFI affect the efficiency/inefficiency of MFIs?

- Is there any difference of efficiency due to the type of MFIs?

- Is MFIs in Pakistan are moving away from their real mission?

Remaining paper has the following structure; Part II will explain the Theoretical Background while part III will highlight the method of analysis, part IV will give the elaboration for empirical results and at the end we will draw the conclusion of the study.

\section{Theoretical Background}

Efficiency is one of the Performance measures of a production process, which is based on the production and cost behavior of a production unit. Efficiency is a derivative of production process and productivity. Productivity is a descriptive measure of performance, and Efficiency is a normative measure. The function of efficiency is a criterion function that has a finite maximum value attainable over the feasible set of the choices variables, which is used as a benchmark to assess the efficiency of a decision-making unit (DMU).The closer the actual value to the maximum attainable value, the greater is its efficiency (Daraio \& Simar, 2007). Though the theme of productive efficiency has been under discussion since Adam Smith's badge of researchers and may be 
earlier in different contour, yet a meticulous investigative approach to the measurement of efficiency in production is derived from the effort of Koopmans (1951) and Debreu (1951), and empirically applied by Farrell (1957). After several modifications, preliminary by Farrell (1957), several approaches for efficient frontier evaluation and efficiency score computation have been implemented. Efficient frontier estimation and efficiency score calculation have been developed for comparing the productivity of different productive units. Green (1997), elucidated that frontier production function is an extension of the familiar regression model; representing an ideal situation for attainable maximum output or minimum cost of producing that output or maximum profit given the prices for input and output. Further that the estimation of frontier functions is the econometric exercise of making the empirical implementation consistent with the underlying theoretical proposition that no observed agent can exceed the ideal; all observations will be positioned within the theoretical extreme. The extent to which observed agents gain/fail to achieve the theoretical ideal indicates it efficiency/inefficiency and that estimated model of production, cost or profit is a way to the target of measuring efficiency/inefficiency.

A derivation of the efficiency frontier function given by Greene (2005b), assumed Producers as price takers in their input markets. Then a single output production frontier became as;

$$
y \leq f(\mathbf{x})
$$

Where " $y$ " is a production function of the single output, using input vector " $\mathrm{x}$ ".

An output based Debreu-Farrell style measure of technical efficiency became as

$$
T E(y, \mathbf{x})=\frac{y}{f(\mathbf{x})} \leq 1 .
$$

By technical efficiency, Greene wants to make out the relationship between observed production and some ideal or potential production. Following the Debreu-Farrell interpretation of econometric framework, a production function became as;

$$
y_{i}=f\left(\mathbf{x}_{i}, \boldsymbol{\beta}\right) T E_{i},
$$

Where $0<\mathrm{TE}\left(\mathrm{y}_{\mathrm{i}}, \mathrm{x}_{\mathrm{i}}\right) \leq 1, \beta$ is the vector of parameters of the production function to be estimated, and ' $i$ ' indexes the $i^{\text {th }}$ of $\mathrm{N}$ firms in a sample to be analyzed. The production model is linear in the logs of the variables, so the empirical foil of the structure became as

$$
\ln y_{i}=\ln f\left(\mathbf{x}_{i}, \boldsymbol{\beta}\right)+\ln T E_{i}=\ln f\left(\mathbf{x}_{i}, \boldsymbol{\beta}\right)-u_{i}
$$

Where $u_{\mathrm{i}} \geq 0$ is a measure of technical inefficiency since $u_{i}=-\ln T E_{i} \approx 1-T E_{i}$.

And $\quad \mathrm{TE}_{\mathrm{i}}=\exp \left(-u_{i}\right)$.

This frontier function derivation is consistent with Debreu's (1951), and Farrell's (1957) efficiency measures, and provides a simple means for computing the distance to the frontier.

The applied researchers now use the combine fundamental theoretical propositions with a practical econometric framework to approximate efficiency. There are different models and methods for efficiency analysis in exercise now; According to Ray and Mukherjee (2004), we can classify efficiency frontier models based on functional form, data used and presence of noise.

- Based on the functional form of the frontier the classification in models can be made as parametric and Non-Parametric models. Parametric model includes, stochastic frontier analysis, Thick frontier analysis and DFA. Whereas, non-parametric include, free disposal hull and Data envelopment analysis.

- Based on the presence of noise in the classification in models can be made as Deterministic Models and Stochastic Models. The presence and absence of noise in the sample data define frontier function and models accordingly.

- Based on the type of data analyzed the classification in the models can be made as Cross-sectional Models and Panel data models. All types of data can be used for frontier model formulation, but specifications of the models will be different according to the data. 


\section{Methodology}

We used one of parametric techniques-SFA in our study. which is econometric approach, specifies a functional form for the cost, profit, or production function and gives a composed error model where inefficiencies are assumed to follow an asymmetric distribution, while random error follows a symmetric distribution (Greene, 2005b).The main feature of SFA indicates (1) the frontier comprises a specific functional form either Cobb-Douglas, Translog or Fourier Flexible (2) Each functional form is different in the way they separate inefficiency from the random error (3) SFA estimate a function where in addition to inputs and outputs other variables can also be incorporated to describe the structure surrounding the function (4)The regression residuals reflect differences in efficiency and the possible noise affecting the performance(5)In Stochastic Frontier Analysis, to obtain an inefficiency measurement that does not depend on stochastic shocks, error obtained are broken down into two components, one is random error and other is inefficiency error(6)Inefficiencies cannot be negative therefore it is assumed that it follow an asymmetrical distribution either half normal or truncated normal, while random errors follow a symmetrical distribution called standard normal(7)The inefficiency measurement is obtained by the estimated mean average of the conditional distribution of the inefficiency termination.

The efficiency measurement by SFA is a way to locate a microfinance institution (MFI); how much it is actually close to what a best-practice MFI's would have been; for producing the same output under the same conditions. There are two approaches to estimate the frontier and the coefficients of efficiency variables. One is the standard two-step SFA approach of Aigner, Lovell and Schmidt (1977), and Meeusen and Van den Broeck (1977) and the second is the Battese and Coelli (1995) (BC) approach which is one- step. The foremost benefit of the BC model over the other is that it estimates the frontier and the coefficients of the efficiency variables simultaneously in one step, and keep the coefficient save from biases. As Wang and Schmidt (2002) showed that two step method renders biased coefficients, because the method undergo the assumption that the efficiency term is independent and identically truncated-normally distributed in the first step, while in the second step the efficiency terms are assumed to be normally distributed and dependent on the explanatory variables. A second superiority of the BC model over two step approach is that it can be estimated for an unbalanced panel, which increases total size of sample. We are dealing with unbalanced panel in our study therefore BC approach will be more suitable for it. The general BC model stipulates a stochastic frontier with the following characteristics:

- $\quad \ln C_{i, t=} C\left(Y_{i, t}, X_{i, t}, Z_{i, t} ; \beta\right)+U_{i, t}+V_{i, t}$

- $\quad$ where $C_{i, t}=$ total cost MFI $i$ faces at time $t$

- $C\left(Y_{i, t}, X_{i, t}, Z_{i, t} ; \beta\right)=$ cost frontier

- $Y_{i, t},=\operatorname{logarithm}$ of output of MFI $i$ at time $t$

- $X_{i, t,}=$ vector of the logarithm of input of MFI $i$ at time $t$

- $Z_{i, t}=$ MFI specific control variables

- $\quad \beta=$ vector of all parameters to be estimated

- $U_{i, t}=$ captures inefficiency 1

- $V_{i, t}=$ captures measurement error and random effects ${ }^{2}$

- Both $u_{i, t}$ and $v_{i, t}$ are time and MFI specific and represented as:

- $U_{i, t} \sim N^{+}\left(W_{i, t}, \sigma_{u}^{2}\right)$ And

- $\quad V_{i, t} \sim \operatorname{iid} N\left(0, \sigma_{v}^{2}\right)$.

- $\quad W_{i, t}=\delta_{0}+\sum_{n} \delta_{n, i, t} q_{n, i, t}$

Equation (6) models (in) efficiency and its explanatory variables. The "q" in Equation (6) represents the vector of $n$ variables that drive the inefficiency $(W)$ of MFI $i$ at time $t$. The deltas represent the coefficients. Equation (4) and (6) will be solved in one step by using maximum likelihood.

\footnotetext{
${ }^{1}$ The term $u_{i, t}$ captures cost inefficiency and is independent and identically distributed with a half normal distribution.

${ }^{2} v$ captures measurement error and random effects, e.g. good and bad luck, and is distributed as a standard normal.
} 
Selection of inputs and outputs: The efficiency estimates obtained from SFA is highly conditional on the appropriate selection of input and output variables used in defining the frontier. There is a considerable debate in the empirical literature about the selection of input and output combinations. Three basic approaches for financial institutions are used in research. These are the intermediation, production and asset approaches. The intermediation approach views financial institutions mainly as mediators of funds between savers and investors. The production approach emphasizes the role of financial institutions as providers of service for account holders. With the asset approach, outputs are strictly defined by assets and the productivity of loans (Jayamaha \& Mula, 2010). We use an intimidation approach because of MF industry basic services as facilitators for microcredit and managing the loan and assets. Table-I present the inputoutput specification for our model.

Table 1: Input-output variables

\begin{tabular}{|c|c|c|c|}
\hline $\begin{array}{l}\text { Variable/ } \\
\text { Intermediation Approach }\end{array}$ & Definition & Input & Output \\
\hline Cost per borrower & It is calculated by operating expense/average number of active borrowers. & Input & \\
\hline Financial Expense & It is calculated as the interest paid for borrowing or debt & Input & \\
\hline Total Assets & Total value of assets at the time of reporting period & Input & \\
\hline Financial margin & $\begin{array}{l}\text { This is the total of revenue from the loan portfolio and other financial assets, } \\
\text { as well as other financial revenues from financial services after paying for the } \\
\text { cost. }\end{array}$ & & Output \\
\hline Gross loan Portfolio & This is the number of loans outstanding at the time of the reporting period & & Output \\
\hline
\end{tabular}

Table 2: (In) Efficiency Determinants

\begin{tabular}{|c|c|c|c|c|}
\hline Variable & Definition & $\begin{array}{l}\text { Hypothesized relationship } \\
\text { to efficiency }\end{array}$ & $\begin{array}{l}\text { Construction of } \\
\text { Variable }\end{array}$ & Value assigns \\
\hline Branches & $\begin{array}{l}\text { It shows the total number of sub-branches } \\
\text { working under a specific organization. }\end{array}$ & Positive & Quantitative & Discrete \\
\hline \multirow[t]{2}{*}{$\begin{array}{l}\text { Employees or } \\
\text { Personnel }\end{array}$} & $\begin{array}{l}\text { This is the number of individuals actively } \\
\text { employed by an MFI. It also includes contract } \\
\text { employees and advisors who dedicate the } \\
\text { majority of their time to the organization } \\
\text { even if they are not on the MFI's roster of } \\
\text { employees. }\end{array}$ & Positive & Quantitative & Discrete \\
\hline & $\begin{array}{l}\text { This is the number of years an organization } \\
\text { has been functioning as a microfinance } \\
\text { provider (MFP) }\end{array}$ & Positive & Quantitative & Continuous \\
\hline Type of MFI & $\begin{array}{l}\text { It indicates the status of MFIs working as a } \\
\text { NGO, Bank, and RSPs etc. }\end{array}$ & Efficiency differences & Qualitative & Discrete \\
\hline $\begin{array}{lr}\text { Average loan } \\
\text { balance per } \\
\text { active borrower }\end{array}$ & $\begin{array}{l}\text { This is used to measure depth of outreach. } \\
\text { The lower the ratio, the more poverty- } \\
\text { focused the MFIs. The higher value of this } \\
\text { variable indicates MFI provide fewer loan to } \\
\text { poor borrower so lesser outreach. }\end{array}$ & $\begin{array}{l}\text { Negative for outreach and } \\
\text { positive for efficiency. }\end{array}$ & Quantitative & Continuous \\
\hline $\begin{array}{l}\text { Number of active } \\
\text { women } \\
\text { borrowers to } \\
\text { total active } \\
\text { borrowers }\end{array}$ & $\begin{array}{l}\text { This indicates the percentage of women } \\
\text { borrower to total active borrowers. The } \\
\text { higher value of this measure indicates more } \\
\text { depth of outreach since lending to women is } \\
\text { associated with lending to poor borrowers. }\end{array}$ & $\begin{array}{l}\text { Positive to outreach and } \\
\text { negative for efficiency. }\end{array}$ & Quantitative & Continuous \\
\hline
\end{tabular}


Determinants of Efficiency: Prior literature provides evidence that the institution's size (Drake \& Hall, 2003), geographic diversification and deposit diversification (Hughes et al., 1996), the size deviation of banks (Lang \& Welzel, 1996), number of branches (Elyasiani \& Mehdian, 1990) influenced efficiency. Studies reported that the size of financial institutions influences their efficiency (Elyasiani \& Mehdian 1990; Hughes et al., 1996; Lang \& Welzel 1996; Bhattacharyya, Lovell \& Sahay 1997; Kwan \& Eisenbeis, 1997; Eisenbeis, Ferrier \& Kwan 1999; Drake \& Hall 2003; Neal 2004). Size is measured in terms of total income (Demirg'uc-Kunt, 1989; Desrochersa \& Lamberteb 2003), total assets (Miller \& Noulas, 1997; Sharma \& Kawadia, 2006), or number of branches (Elyasiani \& Mehdian, 1990). Larger institutions are considered to be operating more efficiently than smaller. We will incorporate two variables, number of Branches and total number of personnel to find the size effect on MFIs efficiency in our study.

Age of MFIs represents the number of years since its establishment. It stands for the experience of an MFI. It is predicted that older MFIs are more experienced and more efficient. Age capture the effect of experience and time on efficiency. Canhoto \& Dermine (2003) also used an age variable to find its relationship with efficiency. Types of MFIs /working status are also considered as efficiency determinant, because of receiving different subsidies/donations/funding amount. Hermes et al. (2011) used a dummy as a proxy for different level of subsidies approximation assuming that same type of MFI has the same level of subsidies, and different level of subsidies has different effects on efficiency. We also incorporated this variable in our study, but in a different context; our study regressed (in) efficiency variable for different types of MFIs to analyze association between both. We considered three peer groups in our study as three types of MFIs that is NGOMFIs, RSPs and MFBs. Table-II summarizes the determinants defined for efficiency evaluation and their hypothesized relationship with efficiency. We estimated the model by applying BC one step SFA for the unbalanced panel data, for the year 2007-2013. For the specification of the function we use intimidation approach, assuming Cobb Douglas functional form. All the variables used after taking the log.

\section{Results and Discussion}

The maximum likelihood estimators for variables, to assess the technical efficiency of 148 MFIs, were estimated by SFA. The best performing firms in Stochastic Frontier Analysis used to make the boundaries and represent potential output for a given set of inputs. In our model, the total cost, total cost per borrowers, total financial expense and total assets were input, whereas net financial margin and Gross loan portfolio were output, to make the boundaries of a frontier. The regression results are given in Table-III. Our estimates of the coefficient for the Cobb-Douglus frontier function in the Table -III depicts that all input elasticity holds expected signs. The elasticity of the total cost to cost per borrower is highest and statistically significant, indicating one percent increase in cost per borrower result in about a 0.64 percent increase in total cost. Therefore MFIs require concentrating more on controlling the unit cost of borrowers in order to reduce their total cost. The estimated financial expense elasticity with cost is very small 0.078 percent, representing that this input is not much of a constriction for efficiency. Gross loan portfolio (GLP) and assets are playing very important role in determining the total cost because both are significant with elasticity of 0.46 and 0.35 respectively. Output from frontier approximated the standard deviations of two error components $=0.495$ and $=0.166$ and Total error variance is reported as $=0.272$. Whereas $\lambda=2.97041$ is indicating the ratio of the standard deviation of the inefficiency component to the standard deviation of the OLS regression model. It provides a justification for using the SFA instead of OLS for idiosyncratic component. The frontier results of the test that "there is no technical inefficiency component in the model" are rejected depicting that most of the residual variance in our model is on account of inefficiency effects. It also confirms that most of the MFIs in Pakistan are operating below the frontier due to which estimated inefficiency of these MFIs is high, and also implies that these inefficiency effects are not stochastic. Our SFA model results are showing a significant improvement over the standard OLS regression results. (Reference table-III Appendix).

Our results showed that almost all the MFIs in Pakistan working below the frontier and not utilizing their resources at their optimal level. Technical efficiency (TE) scores range between 60-90 percent indicating the wastage of input resources up to 10-40 percent, yet GBTI, ORIX, PRSP and NRSPB are below than 60 percent $\mathrm{TE}$, indicating that they are least efficient and wasting their input resources more than that by their counterpart. When we visualized the TE ranking between the years, we found ASAP and BRAC are at the highest with the score of 90 in year 2013, whereas AKHUWAT in 2012 and similarly ASAP, BRAC and KBL in 
2011. We cannot propose any MFI as the best performing as a whole, because during the entire sample period institutions are revealing different efficiency scores. (Reference Table IV). We therefore take the averages of TE for all the MFIs, averages are giving the compact picture based on the mean performance of the industry and individual institutions. (Reference Table-V and Table-VI). Table-V depicts the TE for the individual MFIs. Individually, none of a single institution place on the efficient frontier who proposed as an efficient institution with 100 percent resource utilization. There is room for improvement for all MFIs, because all of them are wasting their inputs or in other words, they are not producing output at their maximum level. On average BRAC performance as compared to other corresponding MFIs is better with the efficiency score of 0.87. It demonstrates that BRAC is using their input 13percent more than that of optimal level or in other words BRAC can produce the same level of output even when utilizing their input 13 percent less than the current level. Basically, this 13percent is extra cost which BRAC is bearing for nothing. They can improve their efficiency by cutting these extra inputs without upsetting their output potentials. In the similar manner we can elucidate for KBL and ASAP, which are second best performers in reference to average TE score, which are using their input 15 percent more for the same level of output. Performance of other institutions can also be detailed in the identical way (Reference Figure 1).

Table-VI indicates the result of average technical efficiency score for the whole industry in Pakistan from year 2007-2013. Though the performance of MF industry is not showing a trend or pattern yet, on average it is improving gradually (Reference Figure 2). Efficiency scores are sensitive to the choice of frontier variables; therefore results will be different for other approximations. The outcomes in (Table-VII) for inefficiency component specify that explanatory variables accounting for the source of technical inefficiency are significant. The parameter for Age indicates that, ceteris peribus, increasing one year of age significantly decreasing technical inefficiency of MFIs in Pakistan. The estimated negative coefficient predicts that on average older and experienced institution are less inefficient as compare to younger one. Coefficient of age is high for MFBs elaborating that older, experienced banks are capable of benefiting from economies of scale which facilitate them in reducing their cost and increasing the efficiency as compared to NGO-MFIs and RSPs. Age is significantly reducing the inefficiency in these three peer groups, yet the average relationship is weak for NGOs and RSPs. Abayie et al. (2011) and Masood and Ahmad (2010) also found age as a significant indicator of efficiency, yet Hassan and Tufte (2001) found age insignificant in determining the efficiency, while doing a study on the Grameen bank efficiency indicator.

The significant negative coefficient of branches for RSPs and NGOs indicate the effect of size on efficiency. It shows a significant decrease in inefficiency with the establishment of one new branch yet this relationship is inverse for MFBs because here increases in branches indicate an increase in inefficiency. The reason, perhaps the high cost of infrastructure for maintaining the banks operation, whereas in case of RSPs and NGOs a small office is adequate to run the operations. On the other hand, Number of personnel adding up the inefficiency in case of RSPs whereas, for NGOs and MFBs relationship is the converse. RSPs are working in the rural areas and incurring a high risk of recovery. Besides, they are dealing with the rural deprived group and managing their costs hardly. In such situation, increasing the number of personnel certainly increases the management cost and inefficiency unless they are planning some innovation, which may reduce the cost in the future for RSPs. For the other two groups MFBs and NGOs, increasing the number of personnel mean a decrease in the inefficiency level, it doesn't mean that it cost nothing for theses two groups but here cost may be less influential than the benefits achieved. Most of the NGOs and MFBs in Pakistan are targeting the low income group residing in semi urban and urban areas. Where there is less risk of recovery and cost constraints as compared to RSPs which are working in rural areas.

Size of MFIs either measured by the number of branches or by personnel has very weak correlation with efficiency or inefficiency of MFIs. Bassem (2008) and Hassan and Tufte (2001) also incorporated size in their study to find the relationship of this variable with efficiency, Bassam found a negative relationship while Hassan and Tufte found no relationship between both. The number of percentage of women borrowers (PWB) and Average loan balance per borrower(ALB) has been used in several studies; Gregoie \& Oswaldo (2003), Cull et al. (2007), Gutiérrez-Nieto et al. (2009) and Hermes et al. (2011, for developing a relationship of outreach with efficiency of MFIs. There is mixed evidence regarding the relationship of PWB, ALB and efficiency. It is assumed in several studies that PWB has positive and ALB has a negative relationship with inefficiency. As Hermes et al. (2011) figured out in his study that a higher percentage of female borrowers are 
associated with a lower financial efficiency of MFIs and lower average loan balances have a negative effect on efficiency. Conversely, Bassem (2008) supported the Women chipping in for increasing efficiency and concluded that an increased percentage of women share in total borrowers improves the overall sustainability and reduces the dependency on donors and government support.

In our study the coefficient of variation of PWB is positive for RSPs and MFBs showing an increase in inefficiency due to focus on women borrower. It also indicates that MFBs and RSPs have the largest share of male clients. Whereas, the negative coefficient of the variable for NGOs is demonstrating that proportion of women is more than man here and also that there exist a negative relationship between inefficiency and women borrowers. This contradiction in the relationship among three per groups is perhaps being due to the structure of MFIs and difference of the target clients and markets. There are many NGOs in Pakistan who have hundred percent women clients, for example, DAMEEN, KASHF and CWCD. Similarly, many other NGOs have a greater proportion of women as compare to man. The negative relationship of inefficiency and women borrower is a good news for those institutions that real aim of microcredit launching is poverty alleviation. Gutiérrez-Nieto et al. (2009) also mentioned the same, MFIs focusing on poverty outreach more also focusing on Women more, and it did not impinge on the efficiency negatively.

The coefficient of the variable, Average loan balance per borrower (ALB), is showing a positive relationship with inefficiency in case of RSPs and NGOs and converse for MFBs. ALB is also used to measure the poverty focus of an institution, where more ALB indicates less focus on poverty. Incongruous fallout in our study is depicting the difference of the main objectives and target clients among MFIs. ALB is low for RSPs and NGOs and also it has a negative relationship with inefficiency, because RSPs is operating in rural areas generally and NGOs is dealing with women primarily, therefore, to avoid the risk of loan recovery both peer groups are enforced to loan in smaller amount. Hence, the relationship is positive with inefficiency for these two peer groups means the higher the ALB higher will be the inefficiency and vice versa. Nonetheless, relationship between MFPs inefficiency and ALB is negative showing more ALB more profit and less inefficiency. MFBs mainly focus on rich borrower as compare to other peer groups, who prefer larger amount of loan balance for their large investment projects, hence large ALB, less cost, extra profit margin and less inefficiency. Gregory \& Oswaldo (2003), also support the same that efficiency is positively related to the average loan.

\section{Conclusion}

An evaluation of the financial strength of MFIs is of much relevance for the sector development of microcredit units, particularly in developing countries. Therefore, we address the issue of quantitative assessment of efficiency for MFIs. In order to see whether MFIs in Pakistan are working efficiently or not, we evaluated the MFIs by applying the SFA technique. Though Microfinance industry in Pakistan is 30 years old having different stories of success and failure, yet due to some major step taken by State Bank of Pakistan and Government of Pakistan, this sector gain supplementary magnitude in the economy of the country for the uplifting of the poor and in income generating activities, more recently. Therefore, through this study, we snapped a current situation of efficiency. To analyze the competency of the sector we regressed different institutional structure variable, e.g.; age, number of branches, number of personnel, status of MFIs, on the inefficiency scores obtained from SFA. We found the average efficiency of the MFIs is low, unstable and trail no specific trend. It is dwindling yet we can expect an improvement over the time because age and inefficiency are negatively related, presenting that with an increase in the age (experience) of established MFIs we can hope for efficiency improvement.

Efficiency is conditional on the status of the MFIs working group. For all variables except age, there exists a dual evidence of a relationship between inefficiency and coefficient of variables, for three peer groups working in Pakistan. The same is the matter with PWB and ALB, two outreach variables, typically incorporated in the previous studies to analyze the focus of MFIs whether it is on financial efficiency only or on a strive for social services also (Mission drift or mission achievement). When we analyzed these two variables in reference to the phenomenon of Mission drift, we found the germs were more strong in the case of MFBs. Which are focusing more on the financial services to the community, not to the poor. Nonetheless, NGOs and RSPs are still focusing on poor community and fulfilling their mission of social services efficiently. They are managing their goal within their resources. We cannot conclude that there is mission drift in the MF 
sector in Pakistan because the intention of NGOs is merely social services, whereas MFBs are taking the social service as a by-product of their financial service. Hence, if MFBs are drifting away from social services, it is not unexpected.

\section{Reference}

Abayie, E., Amanor, K. \& Frimpong, J. (2011). The Measurement and Determinants of Economic Efficiency of Microfinance Institutions in Ghana: A Stochastic Frontier Approach. African Review of Economics and Finance, 2, 149-166.

Aigner, D., Lovell, K. \& Schmidt, P. (1977). Formulation and Estimation of Stochastic Frontier Production Function Models. Journal of Econometrics, 6, 21-32.

Baido, L. (2008). Women in Uganda benefit by freedom from hunger's microcredit/education program, Freedom from hunger. Bay Area International Development Organization.

Bassem, S. B. (2008). Efficiency of Microfinance Institutions in the Mediterranean: An Application of DEA. Transit Stud Rev, 15, 343-354.

Battese, G. E. \& Coelli, T. J. (1995). A Model for Technical Inefficiency Effects in a Stochastic Frontier Production Function for Panel Data. Empirical Economics, 20, 325-332.

Bhattacharyya, A., Lovell, C. A. K. \& Sahay, P. (1997). The impact of liberalization on the productive efficiency of Indian commercial banks. European Journal of Operational Research, 98(2), 250-68.

Canhoto, A. \& Dermine, J. (2003). A note on banking efficiency in Portugal, New vs Old banks. Journal of Banking and Finance, 27, 2087-2098.

CIA. (2011). Country Factsheet-Pakistan. The World Fact Book. https://www.cia.gov/library/publications/the-world-factbook/geos/pk.html

Cull, R., Demirgüç-Kunt, A. \& Morduch, J. (2007). Financial performance and outreach: a global analysis of leading microbanks. Economic Journal, 117, F107-F133.

Daraio, C. \& Simar, L. (2007). Advanced robust and nonparametric methods in efficiency analysis: Methodology and applications (Vol. 4). Springer Science+ Business Media.

Debreu, G. (1951). The Coefficient of Resource Utilization. Econometrica, 19, 273-292.

Demirg'uc-Kunt, A. (1989). Deposit-institution failures: A review of empirical literature, Federal Reserve Bank of Cleveland. Economic Review, 25(4), 1-17.

Desrochersa, M. \& Lamberteb, M. (2003). Efficiency and expense preference in Philippines' cooperative rural banks', Discussion paper 2002-12, Philippine Institute of Development Studies, Philippine

Drake, L. \& Hall, M. J. B. (2003). Efficiency in Japanese banking: An empirical analysis. Journal of Banking and Finance, 27(05), 891-917.

Eisenbeis, R. A., Ferrier, G. D. \& Kwan, S. (1999). The informativeness of linear programming and econometric efficiency scores: An analysis using U.S. banking data. Working paper. Bureau of Business and Economic Research. University of Arkansas.

Elyasiani, E. \& Mehdian, S. M. (1990). A Nonparametric Approach to measurement of efficiency and technological change: The Case of large U.S. commercial banks. Journal of Financial Services Research, 4(2), 157-68.

Farrell, M. (1957). The Measurement of Productive Efficiency. Journal of the Royal Statistical Society A, General, 120, 253-281.

Greene, W. (1997). Frontier Production Functions," in H. Pesaran and P. Schmidt, eds., Handbook of Applied Econometrics, Volume II, Microeconomics, Oxford University Press, Oxford.

Greene, W. (2005b). The Econometric Approach to Efficiency Measurement, in K. Lovell, H. Fried and S. Schmidt, eds., The Measurement of Productive Efficiency, 2nd ed., Oxford, Oxford University Press.

Gregoire, I. R. \& Oswaldo, R. T. (2003). Cost Efficiency of Microfinance Institutions in Peru. A stochastic Frontier Approach. www.Jstore.co

Guitierrez-Nieto, B., Serrano-Cinca, C. \& Molinero, C. M. (2009). Microfinance institutions and efficiency. OMEGA, International Journal of Management Science, 35(2), 131-142.

Hassan, M. K. \& Tufte, D. R. (2001). The X-efficiency of a group based lending institution: the case of Grameen Bank. World Development, 29, 1071-1082.

Hermes, N., Lensink, R. \& Meesters, A. (2011). Outreach and efficiency of microfinance institutions. World Development, 39(6), 938-948. 
Hughes, J. P., Lang, W., Mester, L. J. \& Moon, C. (1996). Efficient Banking under Interstate Branching. Journal of Money, Credit, and Banking, 28(4), 1045-71.

Jayamaha, A. \& Mula, J. M. (2010). Financial practices and efficiency of cooperative rural banks in Sri Lanka. In Proceedings of the 1st International Conference on Business and Information: Researching Realities of Management Phenomenon (ICBI 2010) (pp. 1-25). University of Kelaniya.

Johansen, M. \& Nilsson, C. (2007). Microfinance and poverty reduction: A case study of Grameen Bank and BRAC.

Kabir, M. S. \& Huo, X. (2011). Advancement of Rural Poor Women through Small Entrepreneurship Development: The Case of Bangladesh. International Journal of Business and Management, 6(9), 134.

Khandker, S. R. (2005). Fighting poverty with microcredit: Experience in Bangladesh. New York, NY: Oxford University

Koopmans, T. C. (1951). An analysis of production as an Efficient Combination of Activities, in T.C. Koopmans,ed., Activity Analysis of production and Allocation, Cowles Commission for Research in Economics, Monograph No.13. New York: Wiley.

Kwan, S. \& Eisenbeis, R. A. (1997). Bank risk, capitalization, and operating efficiency. Journal of Financial Services Research, 12(2/3), 117-31.

Ledgerwood, J., Julie, E. \& Candace, N. (2013). The New Microfinance Handbook: A Financial Market System Perspective. Washington, DC: World Bank. doi: 10.1596/978-0-8213-8927-0.

Lang, G. \& Welzel, P. (1996). Efficiency and technical progress in banking: Empirical results for a panel of German Cooperative Banks. Journal of Banking and Finance, 20, 1003-23.

Masood, T. \& Ahmad, M. (2010). Technical Efficiency of Microfinance Institutions in India-A Stochastic Frontier Approach. Technical Efficiency of Microfinance Institutions in India-A Stochastic Frontier Approach (October 8, 2010).

Meeusen, W. \& van den Broeck, J. (1977). Efficiency Estimation from Cobb-Douglas Production Functions with Composed Error. International Economic Review, 18, 435- 444.

Miller, S. M. \& Noulas, A. G. (1997). Portfolio mix and large-bank profitability in the USA. Applied Economics, $29(4), 505-12$.

Neal, P. (2004). X-efficiency and productivity change in Australian banking. Australian Economic Papers, 43(2), 174-92.

Pakistan Microfinance Network. (2011). Microwatch - A Quarterly Update on Microfinance in Pakistan. Issue 11: (Jan-Dec 2011). Islamabad, Pakistan Microfinance Network.

Pakistan Microfinance Network. (2013). Microwatch - A Quarterly Update on Microfinance in Pakistan. Issue 11: (Jan-Dec 2013). Islamabad, Pakistan Microfinance Network.

Ray, S. \& Mukherjee, K. (2004). Comparing Parametric and Nonparametric Measures of Efficiency: A Reexamination of the Christensen and Greene Data. Journal of Quantitative Economics, 11, 155-168

Sharma, G. \& Kawadia, G. (2006). Efficiency of urban cooperative banks of Maharashtra: a DEA analysis. The ICFAI Journal of Bank Management, 5(4), 25-38.

State Bank of Pakistan. (2009). Report of the committee on rural finance. Karachi, State Bank of Pakistan.

Wang, H. J. \& Schmidt, P. (2002). One-step and two-step estimation of the effects of exogenous variables on technical efficiency levels. Journal of Productivity Analysis, 18(2), 129-144.

\section{Appendix}

Table 3: Results for SFA Frontier Variables

\begin{tabular}{lcccccc}
\hline Total Cost & Coefficient & Std. Err. & $\mathbf{Z}$ & $\mathbf{P}>|\mathbf{z}|$ & [95\% Conf. Interval] \\
\hline Total Assets & .3549057 & .0579973 & 6.12 & 0.000 & .2412331 & .4685783 \\
Financial Expense & .0784638 & .0265947 & 2.95 & 0.003 & .0263391 & .1305886 \\
Cost per borrower & .6387881 & .0467596 & 13.66 & 0.000 & .5471409 & .7304353 \\
Financial Margin & -.0344596 & .0477496 & -0.72 & 0.470 & -.1280471 & .0591279 \\
Gross loan Portfolio .4617526 & .0615917 & 7.50 & 0.000 & .3410352 & .582470
\end{tabular}


Table 4: Technical Efficiency Scores 2007-2013

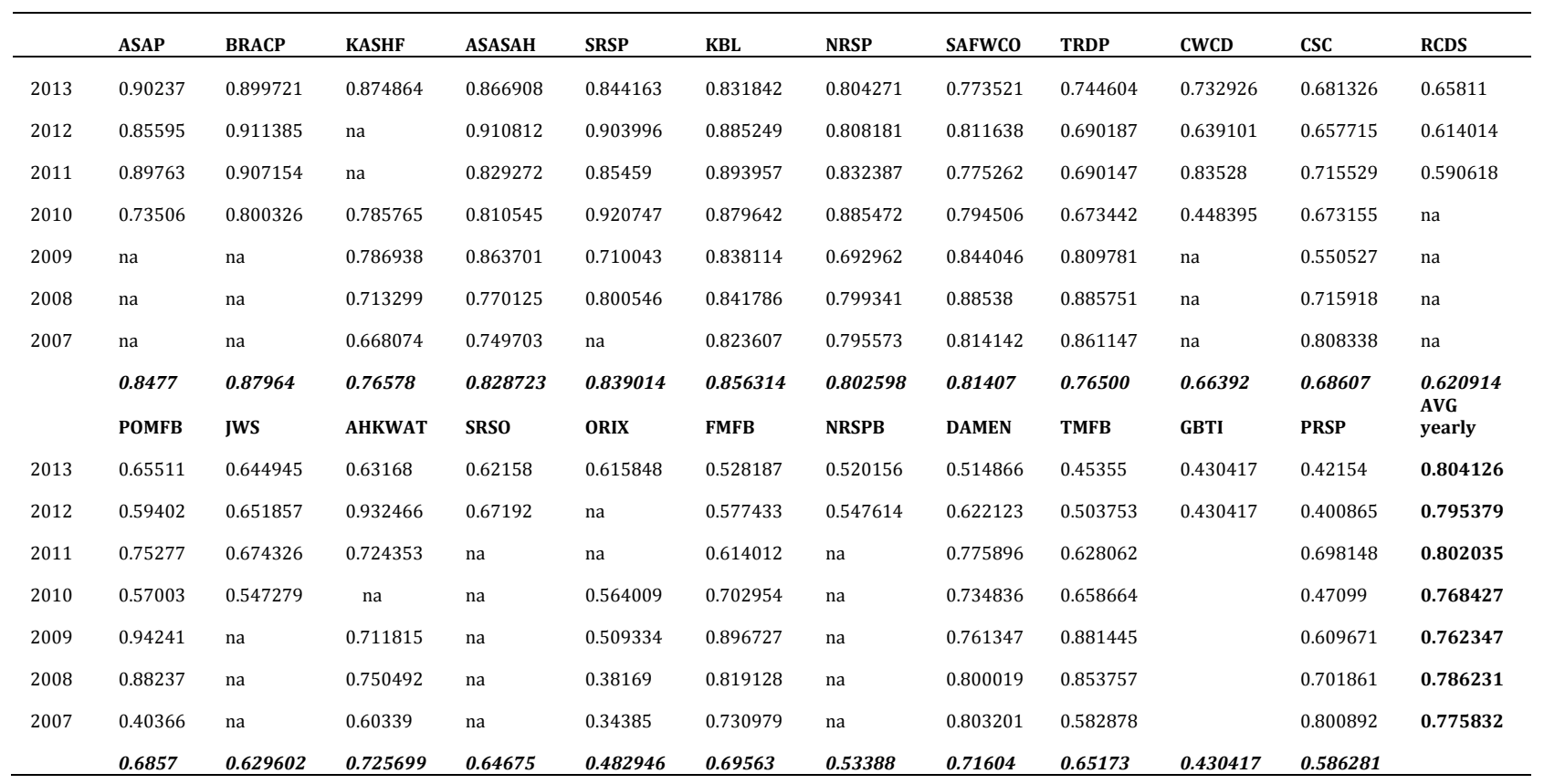

Figure 1: Average TE score by each MFI

\section{AVG EFFICENCY OF MFIS}

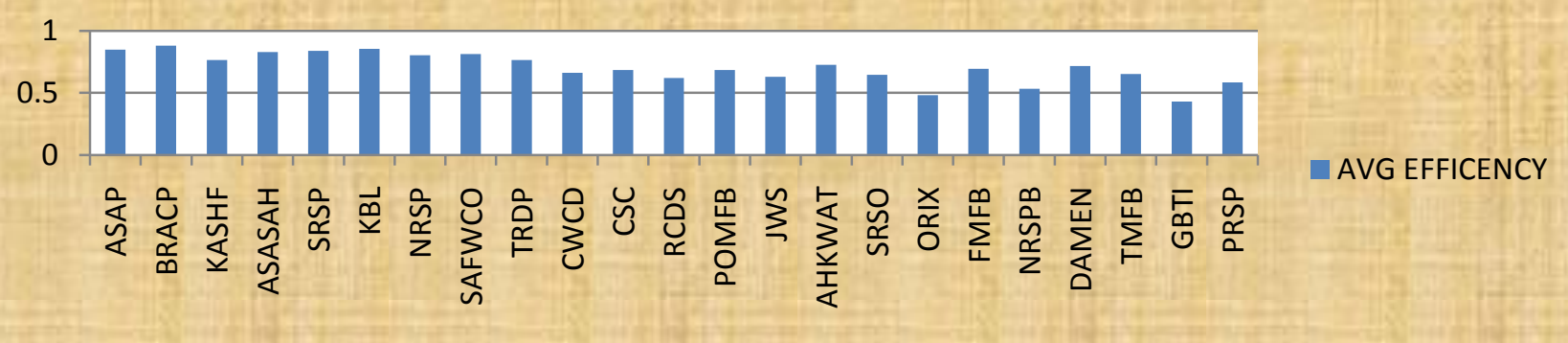

Figure 2: Average Efficiency of the Sector

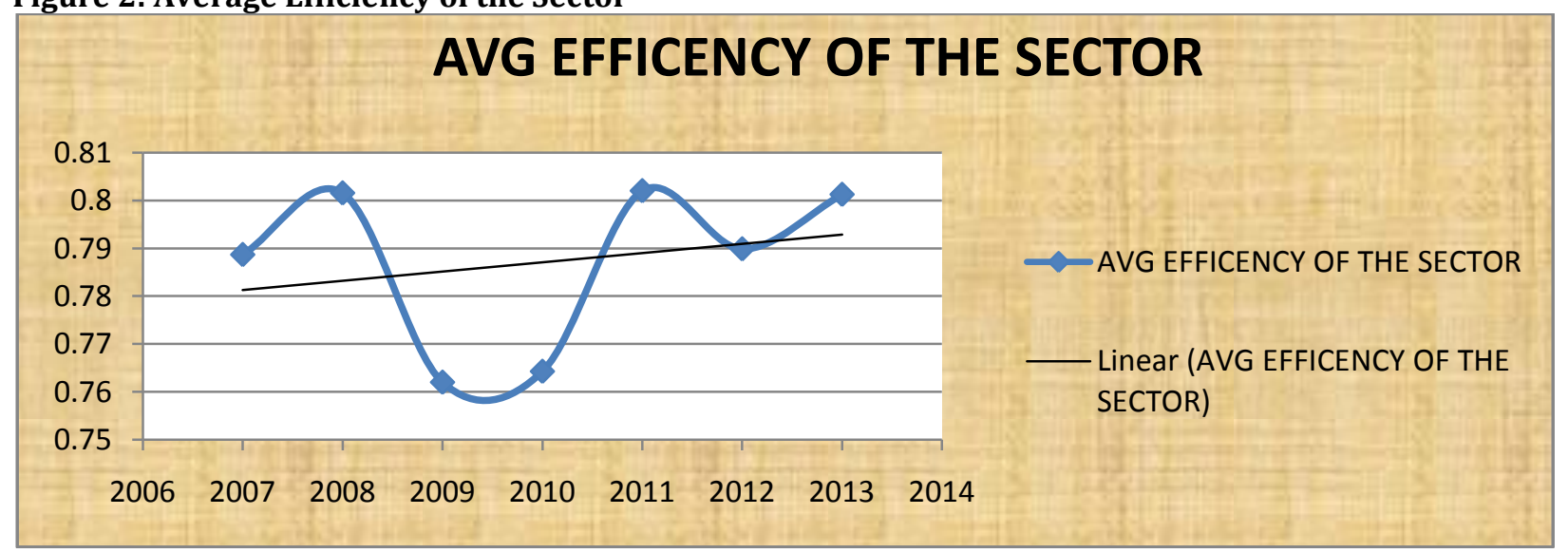


Table 5: Relationship of inefficiency coefficient with Type of MFPs

\begin{tabular}{llll}
\hline Variable & RSPs & NGO MFI & MF BANK \\
\hline Age & $-0.072(0.04)^{* *}$ & $-0.029(0.09)^{* * *}$ & $-0.221(0.06)^{* * *}$ \\
Branches & $-0.015(0.01)^{*}$ & $-0.022(0.00)^{*}$ & $0.003(0.05)^{* *}$ \\
Personnel & $0.0281(0.2)^{* *}$ & $-0.014(0.03)^{* *}$ & $-0.043(0.00)^{*}$ \\
Women Borrowers/Borrowers & $0.0141(0.01)^{*}$ & $-0.004(0.07)^{* * *}$ & $0.0015(0.00)^{*}$ \\
Average loan Balance/Borrower & $0.0612(0.02)^{* *}$ & $0.045(0.12)^{* * *}$ & $-0.066(0.09)^{* * *}$ \\
& & & \\
\hline
\end{tabular}

$*, * *, * * *$ indicates significance at $1 \%, 5 \%$ and $10 \%$ 